\title{
Management of Unstable Distal Radius Fractures: A Survey of Hand Surgeons
}

\author{
Ara A. Salibian, MD ${ }^{1}$ Karl C. Bruckman, MD, DDS ${ }^{1} \quad$ Jonathan M. Bekisz, MD ${ }^{1} \quad$ Joshua Mirrer, MD ${ }^{1}$ \\ Vishal D. Thanik, $\mathrm{MD}^{1}$ Jacques $\mathrm{H}$. Hacquebord, MD ${ }^{1,2}$ \\ ${ }^{1}$ Hansjörg Wyss Department of Plastic Surgery, New York University \\ Langone Health, New York, New York \\ 2 Department of Orthopaedic Surgery, New York University Langone \\ Health, New York, New York \\ Address for correspondence Jacques H. Hacquebord, MD, Hansjörg \\ Wyss Department of Plastic Surgery, Department of Orthopaedic \\ Surgery, New York University Langone Health, 305 East 33rd Street, \\ New York, NY 10016 (e-mail: Jacques.hacquebord@nyumc.org).
}

J Wrist Surg 2019;8:335-343.

\begin{abstract}
Keywords

- distal radius fracture

- fracture immobilization

- volar plate

- hand surgery

- early mobilization

Background Length of immobilization after operative fixation of unstable distal radius fractures and management in elderly patients is an area of debate.

Purpose The purpose of this study is to delineate common practices of fellowshiptrained hand surgeons and how they compare with current evidence-based protocols. Methods Surveys were distributed to American Society for Surgery of the Hand members on preferred methods of fixation, postoperative immobilization, and variations in treatment of elderly patients with unstable distal radius fractures. Responses were analyzed in comparison to a literature review. Subgroups were compared with regard to training, practice type, and years in practice.

Results Four-hundred eighty-five surveys were analyzed. Volar fixed-angle plating was the most common choice of fixation (84.7\%). Patients are most often immobilized for 1 to 2 weeks $(40.0 \%)$ with range of motion (ROM) therapy begun most commonly between 1 and 4 weeks (47.2\%). The majority of surgeons do not treat fractures differently in patients more than 65 years old. Physicians with more than 20 years of experience were significantly more likely to begin wrist ROM sooner with volar plating versus other fixation techniques compared with physicians with less than 20 years of experience ( $40.7 \%$ vs. $34.2 \%$, respectively). Also, physicians in academic-only practices were more likely to immobilize patients for a shorter time after volar plating compared with those in privademics.

Conclusion Volar fixed-angle plating is the dominant fixation method for unstable distal radius fractures among fellowship-trained hand surgeons. Elderly patients are not treated more conservatively and rigid immobilization after operative fixation remains the treatment of choice despite current evidence-based protocols.
\end{abstract}

Distal radius fractures are the most common fractures of the upper extremity ${ }^{1,2}$ and can be a cause of significant morbidity and functional impairment when not properly treated. ${ }^{3}$ Operative fixation remains the principal method of treatment for unstable distal radius fractures to achieve anatomic reduction of articular surfaces, stable fixation, and subsequent early mobilization. ${ }^{4}$ Open reduction and internal fixation (ORIF) of unstable distal radius fractures has gained popularity over the last several years. Single volar fixed-angle constructs ${ }^{5}$ as well as fragment-specific fixation ${ }^{6}$ have demonstrated favorable outcomes with respect to earlier functional recovery compared with external fixation and pinning techniques. ${ }^{7,8}$ However, received

May 20, 2018

accepted after revision

October 8, 2018

published online

November 16, 2018
Copyright $\odot 2019$ by Thieme Medical Publishers, Inc., 333 Seventh Avenue, New York, NY 10001, USA. Tel: +1(212) 584-4662. 
long-term results remain similar between different methods of fixation, ${ }^{7,9,10}$ and larger meta-analyses, that have combined data from multiple studies to create weighted, well-powered analyses of effects, have suggested little clinically significant differences in outcomes. ${ }^{11,12}$

Distal radius fractures are particularly common in the elderly female population secondary to the sequelae of osteoporosis. ${ }^{13}$ Recently, more conservative management has been advocated in older patients with lower functional demands. Studies have demonstrated that closed reduction and casting have similar subjective and functional outcomes as ORIF in this population, ${ }^{14,15}$ though these fracture patterns traditionally would warrant operative fixation.

Many aspects of the postoperative care of unstable distal radius fractures are also evolving. Early mobilization has long been a mainstay of fracture treatment after acceptable fixation. ${ }^{16}$ Reported lengths of rigid immobilization after operative fixation vary significantly in the literature, ranging from no immobilization, ${ }^{17,18}$ to other arbitrary lengths such as two ${ }^{19}$ and four weeks. ${ }^{20}$ Accelerated active motion protocols have also been suggested to improve return to function ${ }^{21}$; however, studies are conflicting on the functional benefits of earlier therapy.

Despite well-established principles for the treatment of unstable distal radius fractures, several aspects in the continuum of management of these injuries remain unclear, particularly with regard to postoperative mobilization of fixated fractures and treatment within specific patient populations. The purpose of this study is to investigate the state of treatment of unstable distal radius fractures in the United States with regard to operative fixation techniques, postoperative immobilization, and conservative management in patients with lower functional demands by means of surveying fellowship-trained hand surgeons. Additionally, this study serves to compare these practices to current evidence-based protocols, or clinical recommendations supported by high-level research studies. Obtaining a better understanding of the current management in the practicing population will serve two purposes: (1) to assess the impact of recent studies advocating changes in traditional treatment algorithms and (2) guide research that identifies optimal postoperative management and helps standardize care.

\section{Methods}

\section{Survey Instrument}

An anonymous, 13-item, multiple-choice online research survey was developed by the senior authors to query current practices of American Society for Surgery of the Hand (ASSH) members with regard to operative fixation of unstable distal radius fractures, postoperative immobilization and range of motion (ROM) therapy, and treatment of unstable fractures in the elderly population. Study approval was obtained from the Institutional Review Board (16-01394).

The survey consisted of three sections pertaining to (1) participant demographics, (2) preferred methods of fixation, and (3) postoperative immobilization protocols (-Supplementary Figs. 1, 2, 3, available in the online version). Participant demographics included questions on surgeon training, years in practice, and type of practice. Preferences for operative fixation focused on preferred type of rigid fixation for operative distal radius fractures defined as unstable fracture patterns and/or those with significant intra-articular step-off. Questions on postoperative immobilization addressed type of immobilization after operative fixation, length of rigid immobilization, and initiation of ROM therapy. Questions also longitudinally addressed variance in protocols with volar fixed-angle plate fixation and differing practices in the elderly population ( $>65$ years old).

Contact information was obtained for all physician ASSH members. Individuals from all training backgrounds and practice settings were included in the study. Respondents were excluded if they were currently in residency or fellowship training and/or had zero years of post-fellowship experience. An email was sent to all prospective study participants twice over the period of 1 month with an invitation to complete the survey on Google Forms (Google Inc., Mountain View, CA) via a directly embedded link.

\section{Statistical Analysis}

Descriptive statistics were examined for all respondents as well as for subgroups of survey participants based on the number of years in practice (greater or less than 20 years of post-training experience), residency training background, and practice setting (academic, private, etc.). Differences in response patterns among these subgroups were analyzed using Pearson's chi-squared test with significance for the omnibus test statistic set at an $\alpha=0.05$. When a significant $p$ value was obtained, raw, standardized, and adjusted standardized residuals were calculated to determine cells making the greatest contribution to the observed difference.

\section{Results}

\section{Respondent Demographics}

Four-hundred eight-five complete surveys were received and analyzed (19.9\% response rate). The majority of surgeons were trained in Orthopaedic Surgery (82.3\%) and respondents had an average of 17.4 years in practice (-Table $\mathbf{1}$ ). The respondents were most likely to work in exclusively private practice (35.9\%), followed by private practice with academic affiliation or privademics (29.0\%), and exclusively academic (18.9\%).

\section{Operative Methods}

Volar fixed-angle plating was the most common method of preferred operative fixation of unstable distal radius fractures (85.1\%) among respondents followed by fragment-specific fixation (7.2\%) (-Fig. 1). Preferences for operative fixation in elderly patients were similar, with olar fixed-angle plating preferred by nearly three-quarters of respondents (74.4\%). Only $5.8 \%(n=28)$ of surgeons indicated they prefer nonoperative immobilization of unstable distal radius fractures in this population. When opting to utilize nonoperative immobilization in this population, $43.3 \%$ of surgeons opted for a period of immobilization between 4 and 6 weeks and $41.8 \%$, between 6 and 8 weeks. 
Table 1 Respondent demographics

\begin{tabular}{|c|c|}
\hline \multicolumn{2}{|l|}{ Years in practice $(n=485)$} \\
\hline Mean \pm SD & $17.4 \pm 11.6$ \\
\hline Median & 17 \\
\hline Range & $0.5-62$ \\
\hline Interquartile range (Q3-Q1) & 18 \\
\hline \multicolumn{2}{|c|}{ Area of primary residency training $(n=485)$} \\
\hline Orthopaedic surgery & $399(82.3 \%)$ \\
\hline Plastic surgery & $66(13.6 \%)$ \\
\hline General surgery & $18(3.7 \%)$ \\
\hline Other & $2(0.4 \%)$ \\
\hline \multicolumn{2}{|l|}{ Practice setting $(n=482)$} \\
\hline Academic only & $91(18.9 \%)$ \\
\hline $\begin{array}{l}\text { Private with academic } \\
\text { affiliation-"Privademics" }\end{array}$ & $140(29.0 \%)$ \\
\hline Private practice only & $173(35.9 \%)$ \\
\hline Hospital-employed & $66(13.7 \%)$ \\
\hline Retired & $5(1.0 \%)$ \\
\hline Other & $7(1.5 \%)$ \\
\hline
\end{tabular}

Abbreviation: SD, standard deviation.

\section{Immobilization}

Ninety percent of respondents endorsed using a short arm cast or splint after volar fixed-angle plating of an unstable distal radius fracture, with $46.1 \%$ opting for a removable splint and $42.3 \%$ electing to use a nonremovable short arm cast or splint. "No immobilization" after operative fixation was only selected by $3.9 \%$ surgeons. Surgeons were most likely to immobilize patients for "1-2 weeks" following operative fixation (40.1\%), followed by "4- 6 weeks" (24.2\%), and then "greater than 2 but less than 4 weeks" (22.1\%). Only $7.4 \%$ of respondents immobilized patients for a period shorter than 1 week, while $4.3 \%$ indicated that they do not immobilize patients (-Fig. 2A). Almost $60 \%$ of respondents indicated that they did not change length of postoperative immobilization for other methods of fixation other than volar fixed-angle constructs, while $30.7 \%$ noted a shorter immobilization period after use of a volar fixed-angle plate (-Fig. 2B).

With regard to timing of initiation of wrist ROM therapy, respondents most commonly began therapy between 1 and 4 weeks postoperatively ( $47.7 \%$ ), while only $8.1 \%$ began ROM therapy "immediately postoperatively" (8.1\%) (-Fig. 3A). The majority of surgeons did change timing of initiation of ROM therapy for other methods of fixation (52.8\%), while $37.0 \%$ begin wrist ROM therapy sooner following volar fixed-angle plating (-Fig. 3B).

Differences in practice trends were also explored regarding postoperative immobilization and wrist ROM protocols in elderly patients versus those younger than 65 years of age. The majority of surgeons indicated that they do not treat elderly patients any differently with respect to the length of postoperative immobilization (72.8\%) (-Fig. 4A). Similarly, most surgeons do not treat elderly patients any differently when determining how long after operative fixation to begin wrist ROM therapy (72.4\%) (- Fig. 4B).

\section{Practice Preferences and Surgeon Characteristics}

The population of survey respondents was separated on the basis of number of years in practice into high ( $\geq 20$ years) $(n=209-212)$ and low ( $<20$ years) $(n=271-272)$ experience groups. These groups differed significantly in their postoperative management of patients with unstable distal radius fractures treated by operative fixation with a volar

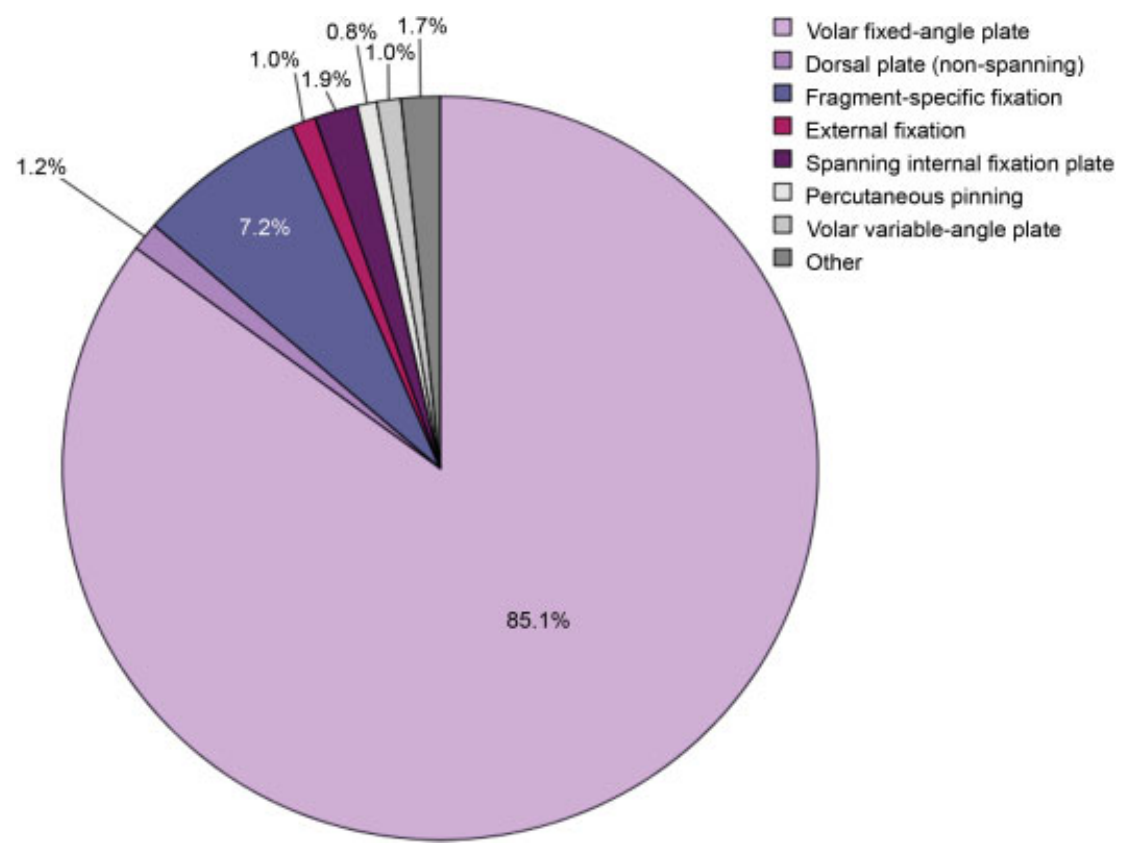

Fig. 1 Distribution of responses for preferred method of fixation of unstable distal radius fractures. The majority of respondents reported volar fixed-angle plates as the preferred fixation construct. 


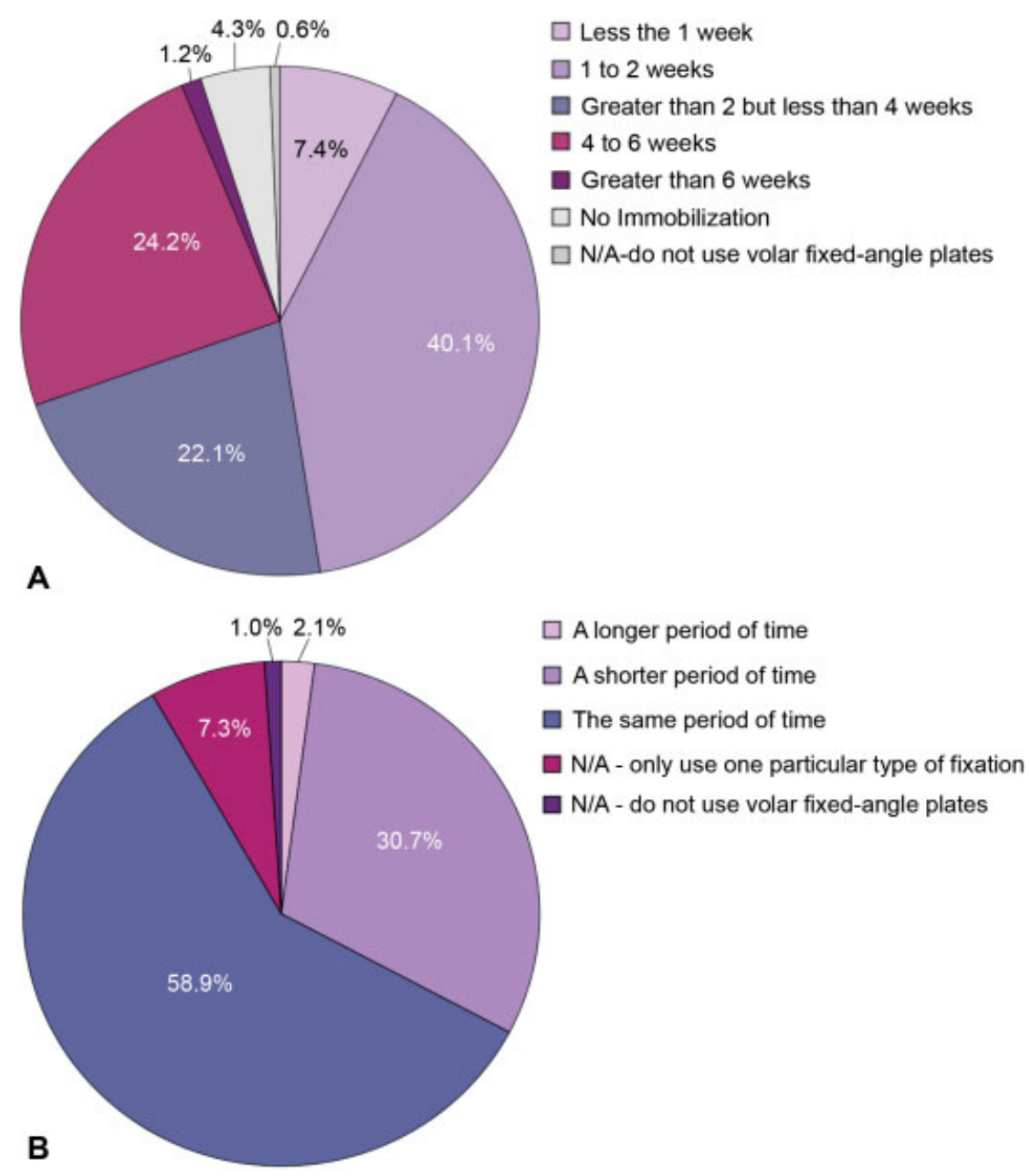

Fig. 2 (A) Distribution of responses for duration of immobilization after operative fixation of unstable distal radius fracture with volar-fixed angle plating and (B) differences in length of immobilization compared with other fixation methods. Immobilization for 1 to 2 weeks postoperatively after operative fixation was the most common response followed by 4 to 6 weeks. The majority of respondents indicated using the same length of immobilization regardless of fixation type.

fixed-angle plate $\left(x^{2}=10.55 ; p=0.032\right)$. A greater percentage of the low experience group (63.2\%) stated that they would keep individuals in rigid immobilization for the same period of time regardless of which method of nonspanning operative fixation was used, compared with $53.3 \%$ in the high experience group. A significant difference in responses was also observed with respect to the initiation of wrist ROM therapy following operative fixation with a volar fixed-angle plate $\left(X^{2}=10.67 ; p=0.031\right)$. Those in the high experience group were more likely to allow patients to begin wrist ROM therapy sooner than when other methods of nonspanning methods of fixation are utilized (40.8\% [high] vs 34.2\% [low]).

Survey respondents were also grouped according to practice setting with significant difference in the length of rigid immobilization following volar fixed-angle plating of an unstable distal radius fracture between the groups comprised of those working in an "academic only" setting $(n=91)$ and those working in "privademics" $(n=140)$ $\left(x^{2}=16.60 ; p=0.011\right)$. More than half $(52.8 \%)$ of those in the "academic only" group stated that they would only place patients in rigid immobilization for 1 to 2 weeks. This contrasted with the "privademics" group, where $31.4 \%$ endorsed a preference for 1 to 2 weeks of immobilization while $51.4 \%$ indicated that they would opt for periods between 2 and 6 weeks.

\section{Discussion}

Despite long-standing principles on the management of unstable distal radius fractures, protocols for postoperative care after fracture fixation remain a point of contention. Review of evidence-based protocols from prospective comparative studies in the current literature suggests that shorter periods of rigid immobilization and earlier initiation of wrist ROM may improve functional outcomes without compromising fixation (-Table 2). ${ }^{18,21}$ However, these findings are not consistent across the literature as studies have conversely shown little benefit to early mobilization. ${ }^{22}$ Current evidence has also demonstrated that conservative management of unstable distal radius fractures in elderly patients may yield equivalent long-term functional outcomes as operative fixation, ${ }^{23}$ though fixation may allow for earlier improved function 


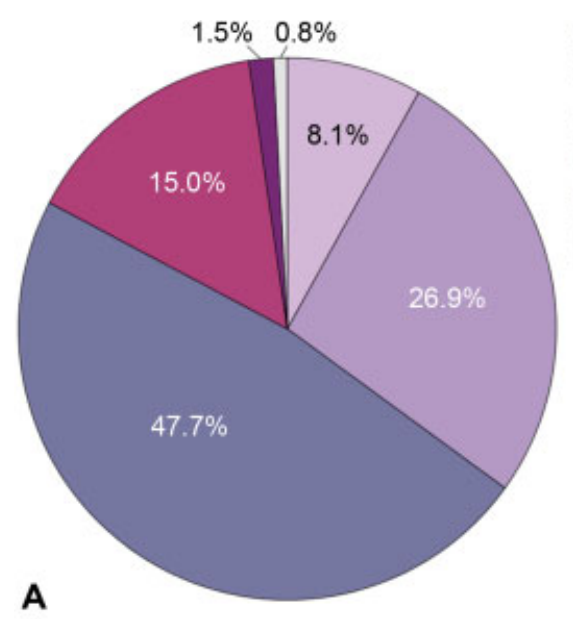

\author{
Immediately post-operatively \\ At 1 week \\ Greater than 1 but less than 4 weeks \\ 4 to 6 weeks \\ Greater than 6 weeks \\ $\square$ N/A - do not use volar fixed-angle plates
}

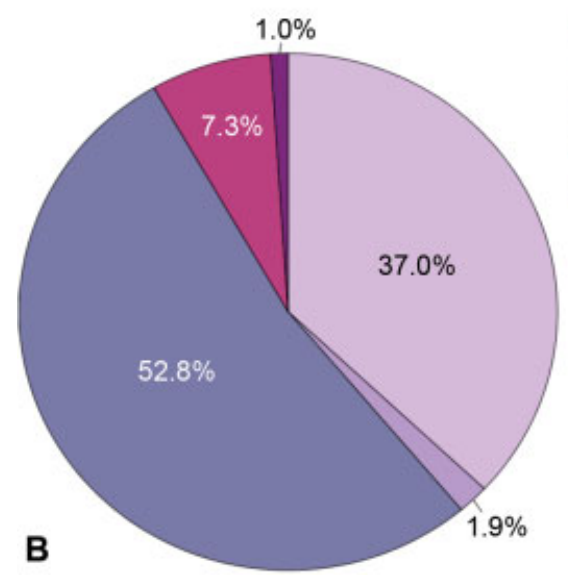

$\square$ Sooner than other methods of fixation

$\square$ Later than other methods of fixation

$\square$ Do not treat differently

N/A - only use on particular type of fixation

EN/A - do not use volar fixed-angle plates

Fig. 3 (A) Distribution of responses for initiation of range of motion therapy after operative fixation of unstable distal radius fracture with volar-fixed angle plating and (B) differences in timing of therapy compared with other fixation methods. The majority of respondents initiated range of motion therapy between 1 and 4 weeks after surgery with no difference in timing with methods of operative fixation other than volar fixed-angle plates.

(-Table 3). ${ }^{23,24}$ While review of the literature yields information on the outcomes of particular institutions and providers, it is still unknown whether practices of physicians nationally reflect these findings.

The purpose of this study was to analyze national practice trends among hand surgeons to determine the impact of changing operative and postoperative protocols in the academic literature on current-day management of unstable distal radius fractures. Members of the ASSH were chosen to be surveyed as an organization consisting of a diverse group of hand surgeons from different training backgrounds and practice models across the country, making it an ideal cohort of providers to assess practice trends. The majority of ASSH hand surgeons surveyed in this study were Orthopaedic Surgery trained. Given that around $81 \%$ of Hand Fellowship programs are Orthopaedic Surgery programs, ${ }^{25}$ this distribution is not unexpected. Mean years in practice after fellowship training were 17.4 years, similar to years of experience among ASSH members in prior studies ${ }^{26}$ and the private office setting was the most common type of practice as with prior surveys of ASSH members. ${ }^{27}$ However, almost $50 \%$ of respondents had some affiliation with academic centers allowing for a broad sampling of different practice types.
The wide variety of fracture patterns of the distal radius precludes the utility of a single, universally superior method of fixation. However, volar plate fixation has demonstrated good functional outcomes with a variety of different fracture patterns ${ }^{7-9,12}$ while avoiding soft tissue complications associated with dorsal plating. This method has gained significant popularity since its introduction in 2002 which is reflected in this survey as volar fixed-angle plates were the preferable method of fixation for unstable distal radius fractures in $84.7 \%$ of respondents.

Results of this survey showed significant variability in length of postoperative rigid immobilization among ASSH members between 1 and 6 weeks. A period of immobilization from 1 to 2 weeks was the most common preference (40.0\%); however, the majority of responses were outside this range. Biomechanical studies have demonstrated the ability of volar plate constructs to withstand early mobilization at 1 week, ${ }^{4}$ and several studies have demonstrated the benefits of early mobilization on return to functionality. ${ }^{18,28,29}$ Despite this, there was a significant discrepancy between the evidence in the literature and national practice trends. Only $11.7 \%$ of survey respondents stated they would remove rigid immobilization prior to 1 week and over $40 \%$ would keep patients in rigid immobilization for greater than 2 weeks. In addition, 

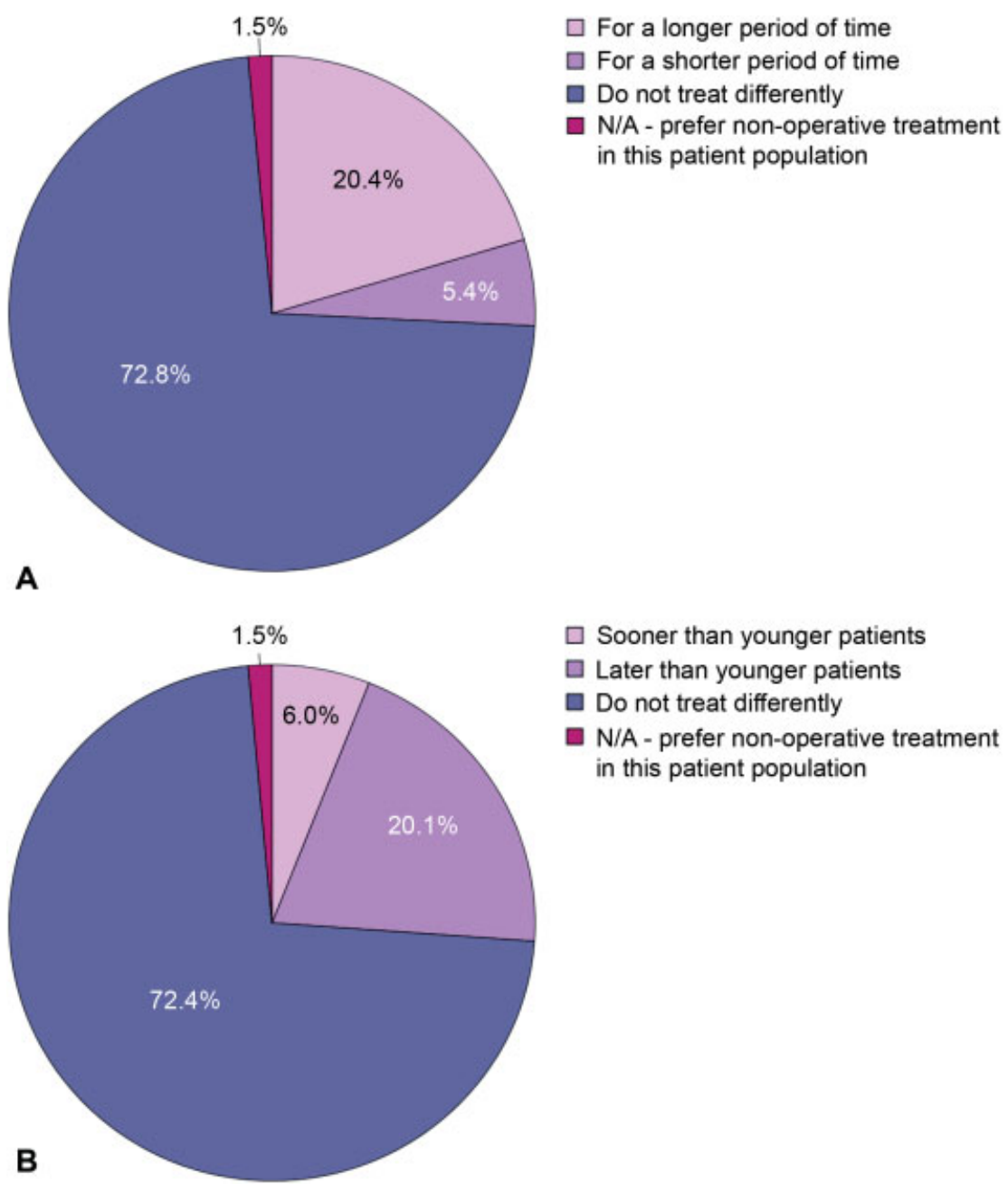

Sooner than younger patients

Later than younger patients

Do not treat differently

- N/A - prefer non-operative treatment in this patient population

Fig. 4 (A) Distribution of responses for length of immobilization and (B) initiation of range of motion therapy in elderly patients (age greater than 65 years old) after operative fixation compared with patients less than 65 years old. The majority of respondents did not endorse any difference in length of immobilization or initiation of range of motion therapy after operative fixation of unstable distal radius fracture in patients greater than 65 years old compared with those less than 65 years old.

volar fixed-angle plating has been shown to be more stable than other fixation constructs allowing for immediate active $\mathrm{ROM}^{30}$; however, the majority of surgeons in our survey stated they would not change the length of immobilization with other methods of fixation. Adherence to similar postoperative mobilization practices regardless of fixation type suggests that practitioners may follow certain familiar postoperative protocols despite changing evidence.

Survey trends with progression of postoperative ROM therapy were similar, in that surgeons were most likely to begin wrist ROM therapy between 1 and 4 weeks (47.2\% of respondents) regardless of the type of fixation (52.4\%). While certain studies have demonstrated the benefits of early and accelerated rehabilitation protocols after operative fixation, ${ }^{21}$ these findings again have not translated to current practices as reflected in this survey.

The rate of ORIF of distal radius fractures in the elderly has increased significantly since the year $2000 .{ }^{31,32}$ Several recent studies, however, have suggested that conservative management of unstable distal radius fractures with cast immobilization in this population yields similar long-term functional outcomes compared with surgical fixation. ${ }^{14,15,23,24}$ Despite the evidence in favor of less-invasive management of lowerfunctional populations, the overwhelming majority of survey respondents endorsed ORIF as their preferred treatment of unstable distal radius fractures in patients greater than 65 years of age (87.8\%). Only 5.8\% reported nonoperative immobilization as a preferred treatment suggesting that evidence from recent studies has not influenced larger-scale practice changes. Evidence, however, has not been completely consistent across studies. Egol et al reported decreased grip strength at 1 year in patients that were treated with casting compared with fixation if they failed conservative management. ${ }^{33}$ Furthermore, studies have suggested that functional outcomes improve earlier with operative fixation in elderly patients despite similar long-term outcomes. ${ }^{14,24}$ It is also important to note, however, that Medicare beneficiaries treated by ASSH members have been shown to have higher rates of internal fixation compared with patients of other physicians, ${ }^{34}$ potentially biasing the observed trends.

The results of this survey demonstrated no discernible consensus among ASSH members on length of postoperative 
Table 2 Studies from 2007 to 2017 comparing outcomes between different postoperative lengths of immobilization after volar plate fixation of unstable distal radius fractures

\begin{tabular}{|c|c|c|c|c|c|c|c|c|}
\hline Authors & Year & Study type & LOE & Size & Fixation & $\begin{array}{l}\text { Immobilization } \\
\text { method }\end{array}$ & $\begin{array}{l}\text { Immobilization } \\
\text { length }\end{array}$ & Conclusions \\
\hline $\begin{array}{l}\text { Quadlbauer } \\
\text { et al }{ }^{18}\end{array}$ & 2017 & $\begin{array}{l}\text { Prospective } \\
\text { randomized } \\
\text { trial }\end{array}$ & 1 & 30 & $\begin{array}{l}\text { Volar } \\
\text { locking } \\
\text { plate }\end{array}$ & $\begin{array}{l}\text { Thermoplast } \\
\text { splint versus } \\
\text { short-arm cast }\end{array}$ & $\begin{array}{l}1 \text { week (splint) } \\
\text { versus } 5 \text { weeks } \\
\text { (cast) }\end{array}$ & $\begin{array}{l}\text { Splint-better: } \\
\text {-Sagittal ROM \& grip } \\
\text { strength (6 months) } \\
\text {-Forearm rotation (6 weeks) } \\
\text {-DASH scores and PRWE } \\
\text { (6 weeks) } \\
\text { No differences: } \\
\text {-Fracture reduction, pain }\end{array}$ \\
\hline $\begin{array}{l}\text { Brehmer and } \\
\text { Husband }^{21}\end{array}$ & 2014 & $\begin{array}{l}\text { Prospective } \\
\text { randomized } \\
\text { trial }\end{array}$ & 1 & 81 & $\begin{array}{l}\text { Volar } \\
\text { locking } \\
\text { plate }\end{array}$ & $\begin{array}{l}\text { Custom wrist } \\
\text { extension splint }\end{array}$ & $\begin{array}{l}4 \text { weeks }+ \text { AR } \\
\text { versus } 6 \text { weeks } \\
+\mathrm{SR}\end{array}$ & $\begin{array}{l}\text { AR group-better: } \\
\text {-Better mobility, } \\
\text { strength, DASH scores } \\
\text { (0-8 weeks) } \\
\text {-Earlier return to function }\end{array}$ \\
\hline $\begin{array}{l}\text { Lozano- } \\
\text { Calderón } \\
\text { et } \mathrm{al}^{22}\end{array}$ & 2008 & $\begin{array}{l}\text { Prospective } \\
\text { randomized } \\
\text { trial }\end{array}$ & 1 & 60 & $\begin{array}{l}\text { Volar } \\
\text { locking } \\
\text { plate }\end{array}$ & $\begin{array}{l}\text { Thermoplastic } \\
\text { volar splint }\end{array}$ & $\begin{array}{l}2 \text { weeks } \\
\text { versus } 6 \text { weeks }\end{array}$ & $\begin{array}{l}\text { No difference: } \\
\text {-Motion, grip strength } \\
\text {-Radiographic parameters } \\
\text {-Gartland and Werley, } \\
\text { Mayo, pain or DASH scores }\end{array}$ \\
\hline
\end{tabular}

Abbreviations: AR, accelerated rehabilitation; DASH, disabilities of the arm, shoulder, and hand; LOE, level of evidence; PRWE, patient-rated wrist evaluation; ROM, range of motion; SR, standard rehabilitation.

immobilization and initiation of ROM therapy after operative fixation of the presented unstable distal radius fracture. Additionally, the majority of surgeons also endorsed treating unstable fractures in the elderly population, as presented in the survey, no different than those in a younger, more functionally demanding cohort. Why then do current practices among fellowship-trained hand surgeons diverge from the evidence presented in the literature? Several possible explanations warrant exploration.

First, surgeons may find the evidence presented in the literature inadequate or of low quality. The majority of the studies addressing postoperative immobilization of distal radius fractures and conservative management in the elderly population are not large, prospective comparative studies. ${ }^{14,28,29,35}$ While randomized prospective studies do exist, for example, with regard to early postoperative mobilization, certain studies present conflicting results, ${ }^{18,22}$ which significantly diminish acceptance of a new paradigm. Surgeons may also not follow evidence reported in the literature, regardless of quality, or may feel their patient population does not reflect that of the literature. Isolated practice patterns may be more likely when sampling a smaller, uniform group of physicians. This survey, however, consisted of large cohort of ASSH members in a variety of different practice settings, making this relatively unlikely. Finally, the implementation of practice change from scientific research takes time. Much of the evidence for changes in management of immobilization and elderly patients has only been recently published, whereas volar plate fixation, on the other hand, has been described for well over 15 years. ${ }^{5}$ The availability of fewer studies on particular interventions may therefore hinder the adoption among the practicing community currently.

Analysis of demographic subgroups showed that physicians with greater than 20 years of post-fellowship experience were significantly more likely to begin wrist ROM sooner with volar plating versus other fixation techniques compared with physicians with less than 20 years of experience. Timing of mobilization after operative fixation is multifactorial, and can be influenced by the particular injury, stability of fixation, and patient tolerance, among other factors. Surgeons utilizing volar plate fixation for longer periods of time may also be more comfortable initiating ROM exercises sooner than those with less experience. Physicians in academic-only practices were also more likely to immobilize patients for a shorter time after volar plating compared with those in privademics. Respondents working within an academic environment may be more exposed to different management protocols that could influence clinical decisions. Prior studies have shown a correlation of surgeon age with fixation type, in which younger surgeons were more likely to perform ORIF of distal radius fractures compared with older surgeons. ${ }^{36,37}$ Fixation type, however, was not found to be influenced by length of years in practice in our study. This may be secondary to inclusion of only distal radius fractures, as well as polling of only ASSH members, who have been shown to favor ORIF of distal radius fractures in prior studies. ${ }^{34,36}$

Certain limitations of this study must be considered upon interpretation of results. Foremost, a survey study inherently offers only descriptive data on trends. Additionally, querying opinions on preferred methods of fixation or immobilization techniques can be difficult to generalize as these interventions often rely on individual variances in fracture patterns or stability of the fixation construct, respectively. Furthermore, survey results cannot delineate among the multitude of different postoperative rehabilitation protocols. Instead, the survey focused on numerous common options for postoperative splints, that still showed significant variability, which is likely exaggerated with more detailed regimes. Similarly, use of age criteria to signify elderly or lower-functional demand patients 
Table 3 Studies from 2007 to 2017 comparing outcomes between conservative management and operative fixation of unstable distal radius fractures in the elderly population

\begin{tabular}{|c|c|c|c|c|c|c|c|c|}
\hline $\begin{array}{l}\text { First } \\
\text { author }\end{array}$ & Year & Study type & LOE & $\begin{array}{l}\text { Study } \\
\text { size }\end{array}$ & $\begin{array}{l}\text { Mean } \\
\text { age } \\
\text { (years) }\end{array}$ & $\begin{array}{l}\text { Immobilization } \\
\text { method }\end{array}$ & $\begin{array}{l}\text { Immobilization } \\
\text { length }\end{array}$ & Conclusions \\
\hline $\begin{array}{l}\text { Chan } \\
\text { et } \mathrm{al}^{24}\end{array}$ & 2014 & $\begin{array}{l}\text { Retrospective } \\
\text { case-control }\end{array}$ & III & 75 & 64.5 & $\begin{array}{l}\text { Short arm cast } \\
\text { versus volar } \\
\text { locking plate }\end{array}$ & 6 weeks & $\begin{array}{l}\text { In active elderly patients, } \\
\text { fixation: } \\
\text {-earlier improved grip } \\
\text { strength and motion } \\
\text { No difference: } \\
\text {-Long-term function } \\
\text { and DASH scores } \\
\text { (12 months) }\end{array}$ \\
\hline $\begin{array}{l}\text { Arora } \\
\text { et al }{ }^{14}\end{array}$ & 2011 & $\begin{array}{l}\text { Prospective } \\
\text { randomized } \\
\text { trial }\end{array}$ & I & 73 & 76.7 & $\begin{array}{l}\text { Short arm cast } \\
\text { versus volar } \\
\text { locking plate }\end{array}$ & 5 weeks & $\begin{array}{l}\text { No difference: } \\
\text {-ROM, pain } \\
\text {-DASH scores and PRWE } \\
\text { (6 and } 12 \text { months) } \\
\text { Fixation: } \\
\text {-Improved DASH score } \\
\text { and PRWE } \\
\text { ( } 6 \text { and } 12 \text { weeks) } \\
\text {-Improved grip strength } \\
\text { all time points } \\
\text {-Better radiographic } \\
\text { results ( } 12 \text { months) } \\
\text {-Higher complications }\end{array}$ \\
\hline $\begin{array}{l}\text { Egol } \\
\text { et } \mathrm{al}^{33}\end{array}$ & 2010 & $\begin{array}{l}\text { Retrospective } \\
\text { case-control }\end{array}$ & III & 90 & 74.5 & $\begin{array}{l}\text { Sugar tong splint } \\
\text { versus volar } \\
\text { locking plate/ } \\
\text { external fixation } \\
\text { (if splint failed) }\end{array}$ & Until healing & $\begin{array}{l}\text { No difference: } \\
\text {-Complications } \\
\text {-Wrist extension ( } 1 \text { year) } \\
\text {-DASH scores, pain } \\
\text { Fixation-better: } \\
\text {-Wrist extension } \\
\text { ( } 24 \text { weeks) } \\
\text {-Grip strength ( } 1 \text { year) } \\
\text {-Radiographic outcome }\end{array}$ \\
\hline $\begin{array}{l}\text { Arora } \\
\text { et } \mathrm{al}^{23}\end{array}$ & 2009 & $\begin{array}{l}\text { Retrospective } \\
\text { case-control }\end{array}$ & III & 114 & 79 & $\begin{array}{l}\text { Cast versus volar } \\
\text { fixed-angle plate }\end{array}$ & $\begin{array}{l}6 \text { weeks } \\
\text { (1-2 weeks plaster } \\
\text { slab }+4-5 \text { weeks } \\
\text { short arm cast) }\end{array}$ & $\begin{array}{l}\text { Fixation: } \\
\text {-Better radiographic } \\
\text { results } \\
\text { No difference: } \\
\text {-Active ROM } \\
\text {-PRWE, DASH, and } \\
\text { Green and O'Brien } \\
\text { scores (4 years) } \\
\text { Casting: } \\
\text {-Less pain }\end{array}$ \\
\hline
\end{tabular}

Abbreviations: DASH, disabilities of the arm, shoulder, and hand; LOE, level of evidence; PRWE, patient-rated wrist evaluation; ROM, range of motion.

is simpler but not ideal. This age cut-off was determined according to prior studies as well as the Medicare age; however, differences in preferred treatments should more accurately be determined by functionality rather than absolute age. While the response rate for the survey was only $20 \%$, the absolute number of responses was high, and reflective of the demographics of ASSH hand surgeons.

\section{Conclusion}

Overall, survey of fellowship-trained hand surgeons that are members of the ASSH showed a general preference for volar fixed-angle plating of unstable distal radius fractures. Recent evidence for improved functional outcomes with early mobilization after operative fixation of distal radius fractures and conservative management of these fractures in elderly patients is not reflected in management preferences reported by hand surgeons. While causative factors are likely multifactorial, there is a need for further high level-of-evidence studies supporting these interventions before changes in management are likely adopted by hand surgeons.

\section{Funding}

None.

Conflict of Interest

None declared.

\section{References}

1 O'Neill TW, Cooper C, Finn JD, et al; UK Colles' Fracture Study Group. Incidence of distal forearm fracture in British men and women. Osteoporos Int 2001;12(07):555-558 
2 Singer BR, McLauchlan GJ, Robinson CM, Christie J. Epidemiology of fractures in 15,000 adults: the influence of age and gender. J Bone Joint Surg Br 1998;80(02):243-248

3 McQueen M, Caspers J. Colles fracture: does the anatomical result affect the final function? J Bone Joint Surg Br 1988;70(04):649-651

4 Koh S, Morris RP, Patterson RM, Kearney JP, Buford WL Jr, Viegas SF. Volar fixation for dorsally angulated extra-articular fractures of the distal radius: a biomechanical study. J Hand Surg Am 2006; 31(05):771-779

5 Orbay JL, Fernandez DL. Volar fixation for dorsally displaced fractures of the distal radius: a preliminary report. J Hand Surg Am 2002;27(02):205-215

6 Geissler WB. Management distal radius and distal ulnar fractures with fragment specific plate. J Wrist Surg 2013;2(02):190-194

7 Wei DH, Raizman NM, Bottino CJ, Jobin CM, Strauch RJ, Rosenwasser MP. Unstable distal radial fractures treated with external fixation, a radial column plate, or a volar plate. A prospective randomized trial. J Bone Joint Surg Am 2009;91(07):1568-1577

8 Rizzo M, Katt BA, Carothers JT. Comparison of locked volar plating versus pinning and external fixation in the treatment of unstable intraarticular distal radius fractures. Hand (NY) 2008;3(02): 111-117

9 Walenkamp MM, Bentohami A, Beerekamp MS, et al. Functional outcome in patients with unstable distal radius fractures, volar locking plate versus external fixation: a meta-analysis. Strateg Trauma Limb Reconstr 2013;8(02):67-75

10 Li-hai Z, Ya-nan W, Zhi M, et al. Volar locking plate versus external fixation for the treatment of unstable distal radial fractures: a meta-analysis of randomized controlled trials. J Surg Res 2015; 193(01):324-333

11 Zong SL, Kan SL, Su LX, Wang B. Meta-analysis for dorsally displaced distal radius fracture fixation: volar locking plate versus percutaneous Kirschner wires. J Orthop Surg Res 2015;10:108

12 Chaudhry H, Kleinlugtenbelt YV, Mundi R, Ristevski B, Goslings JC, Bhandari M. Are volar locking plates superior to percutaneous Kwires for distal radius fractures? A meta-analysis. Clin Orthop Relat Res 2015;473(09):3017-3027

13 Graafmans WC, Ooms ME, Bezemer PD, Bouter LM, Lips P. Different risk profiles for hip fractures and distal forearm fractures: a prospective study. Osteoporos Int 1996;6(06):427-431

14 Arora R, Lutz M, Deml C, Krappinger D, Haug L, Gabl M. A prospective randomized trial comparing nonoperative treatment with volar locking plate fixation for displaced and unstable distal radial fractures in patients sixty-five years of age and older. J Bone Joint Surg Am 2011;93(23):2146-2153

15 Diaz-Garcia RJ, Oda T, Shauver MJ, Chung KC. A systematic review of outcomes and complications of treating unstable distal radius fractures in the elderly. J Hand Surg Am 2011;36(05): 824-835

16 Colles A. On the fracture of the carpal extremity of the radius. Edinb Med Surg J 1814;10(38):182-186

17 Fowler JR, Ilyas AM. Prospective evaluation of distal radius fractures treated with variable-angle volar locking plates. J Hand Surg Am 2013;38(11):2198-2203

18 Quadlbauer S, Pezzei C, Jurkowitsch J, et al. Early rehabilitation of distal radius fractures stabilized by volar locking plate: a prospective randomized pilot study. J Wrist Surg 2017;6(02):102-112

19 Karantana A, Downing ND, Forward DP, et al. Surgical treatment of distal radial fractures with a volar locking plate versus conventional percutaneous methods: a randomized controlled trial. J Bone Joint Surg Am 2013;95(19):1737-1744
20 Osti M, Mittler C, Zinnecker R, Westreicher C, Allhoff C, Benedetto KP. Locking versus nonlocking palmar plate fixation of distal radius fractures. Orthopedics 2012;35(11):e1613-e1617

21 Brehmer JL, Husband JB. Accelerated rehabilitation compared with a standard protocol after distal radial fractures treated with volar open reduction and internal fixation: a prospective, randomized, controlled study. J Bone Joint Surg Am 2014;96(19): $1621-1630$

22 Lozano-Calderón SA, Souer S, Mudgal C, Jupiter JB, Ring D. Wrist mobilization following volar plate fixation of fractures of the distal part of the radius. J Bone Joint Surg Am 2008;90(06):1297-1304

23 Arora R, Gabl M, Gschwentner M, Deml C, Krappinger D, Lutz M. A comparative study of clinical and radiologic outcomes of unstable Colles type distal radius fractures in patients older than 70 years: nonoperative treatment versus volar locking plating. J Orthop Trauma 2009;23(04):237-242

24 Chan YH, Foo TL, Yeo CJ, Chew WY. Comparison between cast immobilization versus volar locking plate fixation of distal radius fractures in active elderly patients, the Asian perspective. Hand Surg 2014;19(01):19-23

25 Goldfarb CA, Lee WP, Briskey D, Higgins JP. An American Society for Surgery of the Hand (ASSH) task force report on hand surgery subspecialty certification and ASSH membership. J Hand Surg Am 2014;39(02):330-334

26 Gaspar MP, Kane PM, Honik GB, Shin EK, Jacoby SM, Osterman AL. Geographic and age-based variations in Medicare reimbursement among ASSH members. Hand (N Y) 2016;11(03):347-352

27 Shubinets V, Gerety PA, Pannucci CJ, et al. Attitude of hand surgeons toward Affordable Care Act: a survey of members of American Society for Surgery of the Hand. J Orthop 2016;14(01):38-44

28 Chung KC, Watt AJ, Kotsis SV, Margaliot Z, Haase SC, Kim HM. Treatment of unstable distal radial fractures with the volar locking plating system. J Bone Joint Surg Am 2006;88(12):2687-2694

29 Osada D, Kamei S, Masuzaki K, Takai M, Kameda M, Tamai K. Prospective study of distal radius fractures treated with a volar locking plate system. J Hand Surg Am 2008;33(05):691-700

30 Smith DW, Brou KE, Henry MH. Early active rehabilitation for operatively stabilized distal radius fractures. J Hand Ther 2004;17 (01):43-49

31 Chung KC, Shauver MJ, Birkmeyer JD. Trends in the United States in the treatment of distal radial fractures in the elderly. J Bone Joint Surg Am 2009;91(08):1868-1873

32 Fanuele J, Koval KJ, Lurie J, Zhou W, Tosteson A, Ring D. Distal radial fracture treatment: what you get may depend on your age and address. J Bone Joint Surg Am 2009;91(06):1313-1319

33 Egol KA, Walsh M, Romo-Cardoso S, Dorsky S, Paksima N. Distal radial fractures in the elderly: operative compared with nonoperative treatment. J Bone Joint Surg Am 2010;92(09):1851-1857

34 Chung KC, Shauver MJ, Yin H. The relationship between ASSH membership and the treatment of distal radius fracture in the United States Medicare population. J Hand Surg Am 2011;36(08): 1288-1293

35 Minegishi H, Dohi O, An S, Sato H. Treatment of unstable distal radius fractures with the volar locking plate. Ups J Med Sci 2011; 116(04):280-284

36 Waljee JF, Zhong L, Shauver MJ, Chung KC. The influence of surgeon age on distal radius fracture treatment in the United States: a population-based study. J Hand Surg Am 2014;39(05):844-851

37 Neuhaus V, Bot AG, Guitton TG, Ring DC. Influence of surgeon, patient and radiographic factors on distal radius fracture treatment. J Hand Surg Eur Vol 2015;40(08):796-804 